\title{
Unit cost of CT scan and MRI at a large tertiary care teaching hospital in North India
}

\author{
Khurshid Rehana, Syed Amin Tabish*, Tariq Gojwari, Reyaz Ahmad, Hakim Abdul \\ Department of Hospital Administration, Sher-i-Kashmir Institute of Medical Sciences, Srinagar, India; \\ *Corresponding Author: amintabish@gmail.com
}

Received 28 September 2013; revised 29 October 2013; accepted 15 November 2013

Copyright (C) 2013 Khurshid Rehana et al. This is an open access article distributed under the Creative Commons Attribution License, which permits unrestricted use, distribution, and reproduction in any medium, provided the original work is properly cited.

\begin{abstract}
Imaging department is an important department of a hospital contributing directly to patient care, providing diagnostic support to all specialties which cannot practice efficiently without their support. Hospital administrators are looking for newer tools to control costs without affecting the quality of patient care. It is well known that the escalation of costs for advanced technology has been dramatic and it has been labeled as one of the culprits for great increase in healthcare costs. A prospective study for a period of six months was carried out for calculation of unit cost of radiological investigations CT head, CT chest, CT abdomen and MRI. Unit costs were computed under direct and indirect costs. The actual cost incurred by the hospital on CT head was Rupees 581.40 (US \$10.89), CT abdomen Rupees 2339.20 (US \$43.83), CT chest Rupees 2339.20 (US \$43.83), and MRI Rupees 4497.50 (US \$84.28). However, in the hospital patients are charged Rupees 900 (US \$16.86) for CT head, Rupees 1200 (US \$22.48) for CT abdomen, Rupees 1200 (US \$22.48) for CT chest and Rupees 2500 (US \$46.85) for MRI. There is a substantial loss of revenue because of subsidies provided to patients in a tertiary care teaching hospital which needs revision of charges.
\end{abstract}

Keywords: Unit Cost; Radiological Investigations; Direct Cost and Indirect Cost

\section{INTRODUCTION}

Cost control is a process of limiting the expenditure either on the production or on distribution, so that the goods may be made available to the ultimate consumer at affordable cost. It is well known that the escalation of costs for advanced technology has been dramatic and it has been labeled as one of the culprits for great increase in healthcare costs [1]. Cost control programmes are not aimed at cutting the quality or quantity of services provided to the patient. They are aimed at increasing the performance efficiency of the healthcare team [2]. The process of cost analysis has become a managerial tool for financial management in hospital. Costing also helps to assess the efficiency and effectiveness of functionaries and their cost implication with a view to contain cost [3]. Health administrators are looking for newer tools to control costs without affecting the quality of patient care. Hospital cost and efficiency should be examined through accounting base studies. Knowledge of unit cost is needed to assist planning for recurrent budget as an indicator of efficiency and to enforce pricing of services [4]. Imaging equipment is very complex now than ever and choice is extensive. The medical institution and the administration of health care institutions are forced to pay close attention to the management of a new kind of technology in a very efficient manner. The importance of imaging modality of investigation has assumed great significance in the past two decades [5]. Newer imaging technologies, CT and MRI are replacing older ones in the evaluation of patients. The impact of this change would be useful in justifying the increase in use of these new technologies and decreasing their inappropriate use should be a priority in efforts that focus on controlling imaging expenditure [6].

As the CT and MRI are costly investigations and an important component of patient care. Hence in planning and managing patient care, attention should be focused on cost and quality of these investigations.

\section{OBJECTIVE}

To find out the Unit Cost of CT scan and MRI investigations at a large tertiary care teaching Hospital (Sheri-Kashmir Institute of Medical Sciences, Srinagar). Unit 
cost is an important tool for Hospital Administrators in planning of services and pricing to fix the user charges.

\section{METHODOLOGY}

A prospective study of six months from first January to thirtieth June, 2009 was carried out in Radiodiagnosis Department of Sher-i-Kashmir Institute of Medical Sciences (SKIMS), Srinagar, which is the Premier Hospital of Jammu \& Kashmir State (deemed University with 700 bedded tertiary care hospital). This apex medical centre also is the lone referral hospital for complex and critical ailments. SKIMS is also imparting higher medical education and actively involved in Biomedical Research.

The costs were considered under direct and indirect costs. Direct costs included material cost, direct labor cost, machine depreciation cost, maintenance costs of equipments, and cost of CT tube in case of CT head. Indirect cost included building cost, electricity cost, water consumption and indirect labor costs.

$$
\text { Unit cost was calculated as }=\frac{\text { Direct cost }+ \text { indirect cost }}{\text { Direct cost }+ \text { indirect cost }}
$$

\subsection{Unit Cost of CT Head}

Direct labor cost includes salary of actual staff working in CT section of Radiodiagnosis department. The staff included Radiologists, technicians and staff nurses. The total direct labor costs for CT head for the study period was Rupees 4, 44,038 (US \$8321.55), which is $13.8 \%$ of the total cost.

Material cost which includes cost of CT film, film covers and other stationary items was Rupees 5, 19,118 (US \$9728.59), which is $16.9 \%$ of total cost.

Machine depreciation cost: The purchase cost of machine mentioned in log books and supply orders was taken from purchase section of Sher-i-Kashmir Institute of medical Sciences. Cost of machine when commissioned in 2000 was Rupees 200, 00,000 (US \$374812.59). The equipment would depreciate at the rate of $10 \%$ per year.

Using the straight line diminishing balance method the depreciation value of equipment for the study period was Rs 3, 38,420 (US \$6342.20), which is $12.08 \%$ of the total cost.

Maintenance cost of the equipment without tube was Rupees 125,000 (US \$2342.57), which is 3.79\% of the total cost.

Cost of CT tube was Rupees 12, 50,000 (US $\$ 23425.78$ ), which is $38.69 \%$ of the total cost.

Indirect labor cost which includes salaries of recaptionist, store clerk and attendants was Rupees 1, 37,996 (US $\$ 2586.13$ ), which is $4.32 \%$ of the total cost.

Electricity cost includes cost of electricity consumption of machine, developer, tube lights and air conditioning. The electricity cost for the study period was Ru- pees 185,940 (US $\$ 3484.63$ ), which is $5.68 \%$ of the total cost

Water cost was Rupees 1842 (US \$34.52), which is $0.056 \%$ of the total cost

Building cost: The rental value for the study period was Rupees 180,000 (US \$3373.31), which is 5.51\% of total cost.

\subsection{Unit Cost of CT Chest/CT Abdomen}

Direct Labour Cost: The total direct labour cost for the CT chest/ CT abdomen for the study period was Rupees 763,594 (US $\$ 14310.23$ ), which is $15.6 \%$ of total cost.

Material Cost: The total material cost for the study period was Rupees 607,836 (US \$11391.22), which is $12.5 \%$ of total cost.

Machine Depreciation Cost: Cost of machine when commissioned was Rupees 43,065,000 (US \$807065.21). Using Straight line diminishing method, the depreciation value of machine for the study period was Rupees $1,739,628$ (US $\$ 32601.72$ ), which is $35.7 \%$ of total cost.

Maintenance Cost: The comprehensive maintenance contract for the study period was Rupees 1,249,998 (US $\$ 23425.74)$, which is $25.6 \%$ of total cost.

Indirect Labour Cost for study period was Rupees 137,996 (US \$2586.13), which is $4.70 \%$ of total cost.

Electricity Cost for the study period was Rupees 189,588 (US \$3552.99), which is 3.89\% of total cost.

Cost of water consumption for the study period was Rupees 1842 (US \$34.52), which is $0.038 \%$ of total cost.

Building Cost: The rental value for the study period was Rupees 180,000 (US \$3373.31), which is $3.69 \%$ of the total cost.

\subsection{Unit Cost of MRI}

Direct Labour Cost for MRI for the study period was Rupees 621,964 (US \$11655.99), which is $13.3 \%$ of total cost.

Material Cost: The total material cost for the study period was Rupees 319,226 (US \$5982.49), which is $5.6 \%$ of total cost.

Machine Depreciation cost: Cost of machine when commissioned in 2007 was Rupees 58,552,000 (US \$1097301.34). Using Straight line diminishing balance method, the deprecation value of machine for the study period was Rupees 2,371,356 (US \$44440.70), which is $41.9 \%$ of total cost.

Maintenance Cost: The comprehensive maintenance contract for the study period was Rupees 1,849,998 (US $\$ 34670.12$ ), which is $32.4 \%$ of total cost.

Indirect Labour Cost for study period was Rupees 137,996 (US $\$ 2586.13$ ), which is $4.02 \%$ of total cost.

Electricity Cost for the study period was Rupees 
217,740 (US $\$ 4080.58$ ), which is $3.89 \%$ of total cost.

Cost of water consumption for the study period was Rupees 1842 (US \$34.52), which is $0.03 \%$ of total cost.

Building Cost: The rental value for the study period was Rupees 180,000 (US \$3373.31), which is $3.2 \%$ of the total cost.

\section{RESULTS}

The actual cost incurred by the hospital to provide CT head services was Rupees 581.40 (US \$10.89) [Figure 1/Table 1]. The direct cost accounts for $84.44 \%$ and indirect cost $15.56 \%$ of the total cost [Figures 2 and 3]. The actual cost incurred by the hospital to provide CT
Chest/Abdomen was Rupees 2339.20 (US \$43.83) [Table 2]. The direct cost accounts for $87.7 \%$ and indirect cost $12.3 \%$ of the total cost. The actual cost incurred by the hospital to provide MRI was Rupees 4447.30 (US \$83.34) [Figure 4/Table 3]. The direct cost accounts for $92.2 \%$ and indirect cost $7.8 \%$ of the total cost.

\section{DISCUSSION}

In the Health sector of many developing countries there is a great wastage of resources because of technical and managerial inefficiency with in hospitals. In order to control the hospital expenditure and improve the efficiency, there is a need to introduce professionalism in

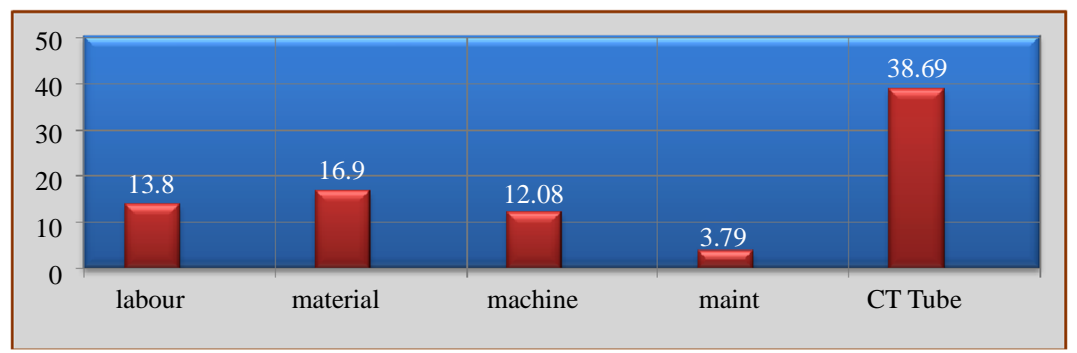

Figure 1. Showing direct cost of CT scan head.

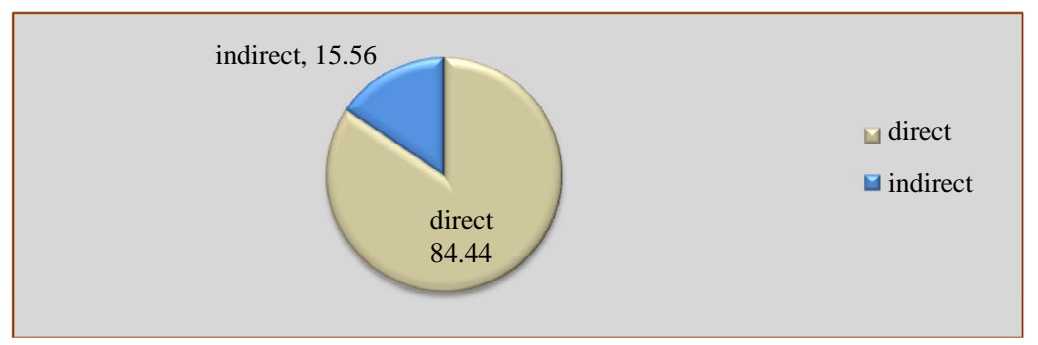

Figure 2. Showing percentage of direct and indirect cost of CT head.

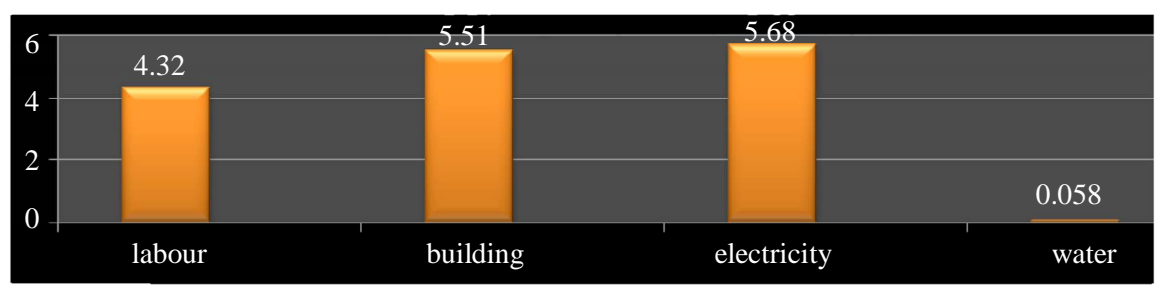

Figure 3. Showing indirect cost of CT scan head.

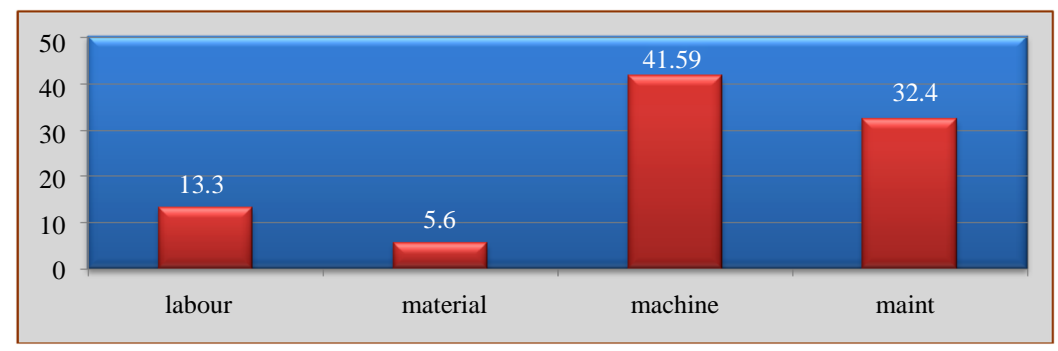

Figure 4. Showing direct cost of MRI. 


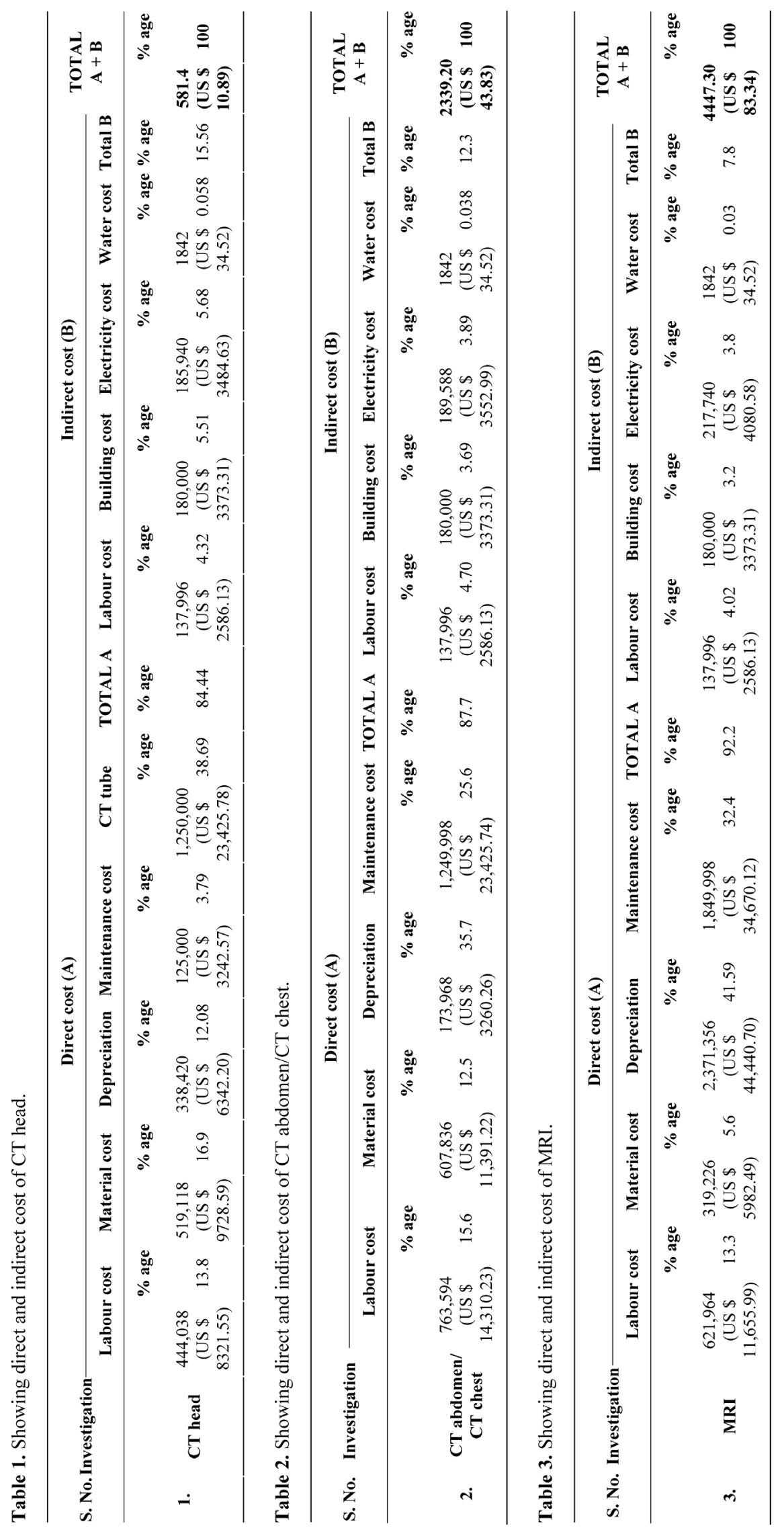


hospital management [7]. Escalating health care expenditure has become a global problem. In most countries cost on health has increased as compared to growth in economy. As users of the hospital services have become conscious and aware of the cost factor, so hospitals need to have health administrators who can work on cost containment in health care without compromising effectiveness of services particularly in these times of competition [8]. Our study revealed that the actual cost incurred by the hospital to provide CT head, CT abdomen, CT chest, and MRI was Rupees 581.4 (US \$10.89), 2339.20 (US \$43.83), 2339.20 (US \$43.83), and Rupees 4447.30 (US \$83.34) respectively. However, in the hospital patients are charged Rupees 900 (US \$16.86), 1200 (US \$22.48), 1200 (US \$22.48), and Rupees 2500 (US \$46.85), for CT head, CT abdomen, CT chest, and MRI respectively. Highest cost was incurred on machinery and maintenance. So our results highlight that technology acquisition is a major challenge for hospital administrators. If we compare our results with a study by Satyashankar et al., the unit cost of MRI was Rupees 5339.67 (US \$100.06), in which direct cost was $85.4 \%$ and indirect cost was $14.6 \%$ [9]. The variance in unit cost per MRI in our study conducted at SKIMS is low because of higher number of investigations, whereas the variance in direct cost is high because the depreciation cost of equipment is high in our study and the building cost was shown higher in the study conducted by Satyashankar et al. However, our MRI results are comparable with the study conducted by Chakravarty et al. in which unit cost of MRI was shown to be Rupees 4129 [10].

\section{CONCLUSION}

Hospitals are becoming technology intensive organizations and technology acquisition is a major challenge for hospital administrators. There is substantial loss of revenue because of subsidies provided to the patients in public hospitals which need revision of charges. Cost of these investigations can be reduced by involving clinicians, radiologists in planning investigations and regular audits, so that only needed investigations are done as per requirement of the patients. Cost saving is an important factor, but it should not be made at the expense of the patient lives. Physicians and healthcare providers are increasingly pressured to contain the cost of Medicare. Such pressures are driven by competition in the market. Thus, it is incumbent upon radiologists to have a basic understanding of the costs of radiology procedures and the factors that determine those costs.

\section{REFERENCES}

[1] Evans, C. (2000) Imaging in the new millennium. Hospital Management International, Sabrecrown Publishing, London, 34-36.

[2] Sharma, R.K. (1995) Cost control strategies in healthcare institutions. Journal of Indian Hospital Association, 32, 161.

[3] Bhaskaran, V.P., Satyashankar, P. and Desmond, D.S.S. (2002) Use of hospital-Accounting based cost studies to aid in better management of resources of CSSD in a large tertiary care. Teaching Hospital. Journal of Academy of Hospital Administration, 14, 15-18.

[4] Amin, T., Mustafa, A. and Rangrez, R.A. (2001) Hospital accounting based cost studies: Indian experience. JAHA, 13.

[5] Gupta, S.K. and Kant, S. (2000) Hospital stores management: An integral approach. Jaypee Brothers Medical Publishers (P) Limited, New Delhi, 134-136.

[6] Yohei, W., Fujii, M. and Hayashi, Y. (2009) Evaluation of errors influencing accuracy in image. Guided Neurosurgery Radiological Physics \& Technology, 2, 121.

[7] Amin, T. (1998) Towards development of professional management of Indian hospitals. Journal of Management in Medicine, 12, 283.

[8] American Hospital Association (1998) Organizing a cost containment committee in hospital AHA catalogue No. 1550, 1.

[9] Satyashankar, P., Kantipudi, S. and Rinkoo, A.V. (2008) Unit costing and break even analysis of MRI facility at a tertiary care teaching hospital. JAHA, 20, 29-35.

[10] Chakravarty, A. and Naware, S.S. (2008) Cost effective analysis for technology acquisition. Medical Journal of Armed Forces of India, 64, 46-49. http://dx.doi.org/10.1016/S0377-1237(08)80146-3 